\title{
Management of first-episode pelvic inflammatory disease in primary care: results from a large UK primary care database
}

\author{
Amanda Nicholson, Greta Rait, Tarita Murray-Thomas, \\ Gwenda Hughes, Catherine H Mercer and Jackie Cassell
}

\begin{abstract}
Background

Prompt and effective treatment of pelvic inflammatory disease (PID) may help prevent long-term complications. Many PID cases are seen in primary care but it is not known how well management follows recommended guidelines.
\end{abstract}

Aim

To estimate the incidence of first-episode PID cases seen in UK general practice, describe their management, and assess its adequacy in relation to existing guidelines.

Design of study

Cohort study.

Setting

UK general practices contributing to the General

Practice Research Database (GPRD).

\section{Method}

Women aged 15 to 40 years, consulting with a first episode of PID occurring between 30 June 2003 and 30 June 2008 were identified, based on the presence of a diagnostic code. The records within 28 days either side of the diagnosis date were analysed to describe management.

\section{Results}

A total of 3797 women with a first-ever coded diagnosis of PID were identified. Incidence fell during the study period from 19.3 to $8.9 / 10000$ person-years. Thirty-four per cent of cases had evidence of care elsewhere, while 2064 (56\%) appeared to have been managed wholly within the practice. Of these 2064 women, $34 \%$ received recommended treatment including metronidazole, and $54 \%$ had had a Chlamydia trachomatis test, but only $16 \%$ received both. Management was more likely to follow guidelines in women in their 20s, and later in the study period.

\section{Conclusion}

These analyses suggest that the management of PID in UK primary care, although improving, does not follow recommended guidelines for the majority of women. Further research is needed to understand the delivery of care in general practice and the coding of such complex syndromic conditions.

Keywords

chlamydia; electronic health records; incidence; pelvic inflammatory disease; primary health care.

\section{INTRODUCTION}

Pelvic inflammatory disease (PID) is a clinical syndrome involving abdominal pain and tenderness, dyspareunia, abnormal bleeding, discharge, and fever. It is predominantly the result of a bacterial (often sexually transmitted) infection ascending from the endocervix to the higher reproductive tract. PID can lead to long-term complications including tubal infertility, ectopic pregnancy, and pelvic pain and it is thought that prompt treatment reduces the risk of such sequelae. ${ }^{1}$ UK guidelines for the treatment and management of PID cover appropriate testing and antibiotic treatment and include suggested outpatient regimens. ${ }^{2-5}$ Although some women in the

A Nicholson, $M S c, P h D, M B B S$, research fellow in primary care epidemiology; J Cassell, FRCP, FFPH, MD, professor of primary care epidemiology, Division of Primary Care and Public Health, Brighton and Sussex Medical School, University of Brighton, Brighton. G Rait, MSc, MD, MRCGP, senior clinical scientist, MRC General Practice Research Framework, London. T Murray-Thomas, MSc, research scientist, General Practice Research Database, The Medicines and Healthcare Products Regulatory Agency, London. G Hughes, BA(Mod), $\mathrm{PhD}$, consultant scientist (epidemiology), Department for Microbiology and Epidemiology of STIs and HIV, Health Protection Agency Centre for Infections, London. CH Mercer, $B S c, M S c, P h D$, senior lecturer, Centre for Sexual Health and HIV Research, Research Department of Infection and Population Health, University College London, London.

Address for correspondence Amanda Nicholson, Division of Primary Care and Public Health, Brighton and Sussex Medical School, Mayfield House Room 322, University of Brighton, Falmer, Brighton BN1 9PH. E-mail: a.c.nicholson@bsms.ac.uk

Submitted: 23 March 2010; Editor's response: 22 April 2010; final acceptance: 25 May 2010

(C)British Journal of General Practice

This is the full-length article of an abridged version published in print. Cite this article as: Br J Gen Pract 2010; DOI: 10.3399/bjgp10X532404. 
UK experiencing the symptoms of PID may seek help in specialist clinics, such as genitourinary medicine clinics, or go direct to secondary care via emergency departments, many are likely to attend their GP., Indeed, analysis of records for patients consulting in general practice have indicated that a substantial and increasing proportion of sexually transmitted infections (STIs) are dealt with in primary care settings. ${ }^{8,9}$ This trend follows England's National Strategy for Sexual Health and HIV, which recommended a greater role for primary care providers in the detection and treatment of STIs. ${ }^{10}$

Little is known about how women with PID are managed in general practice, or how closely management guidelines are followed in this setting. The existing literature is based on self-report questionnaires, which often have very low response rates and are subject to reporting bias. ${ }^{11}$ However they show that guidelines are often not followed. Chlamydia trachomatis is an important causative agent of PID and concern about the burden of $C$. trachomatis infection in men and women aged 15-24 years and the potential long-term sequelae resulted in the National Chlamydia Screening Programme (NCSP) in England. ${ }^{12}$ This programme offers opportunistic screening from various clinical and non-clinical sites. It is not clear how this programme has affected the management of PID. There is a need for recent data to describe delivery of care and inform continuing education.

Research databases of electronic primary care records enable identification of women seen in general practice and given a diagnostic code for PID. The presence of such a code may not always accurately reflect the presence of the clinical condition, but the large body of varied research using these resources suggests that they allow valid examination of real-life patient journeys.

\section{Research objectives}

Using electronic primary care records, the study aimed to estimate the incidence of first-episode PID seen in general practice by identifying a cohort of women consulting with a first-ever episode of PID. It also aimed to describe the management of these patients, within the practice and beyond, and assess its adequacy in relation to existing guidelines, including associations between management and various patient and practice factors.

\section{METHOD}

\section{Data used}

The General Practice Research Database (GPRD) is an electronic database of anonymised longitudinal patient records from general practice. ${ }^{13}$ Established in 1987 , it is a UK-wide dataset covering $5.5 \%$ of the

\section{How this fits in}

General practice has an important role in treating pelvic inflammatory disease. Management guidelines exist, but it is uncertain whether these are followed in general practice. Coded data from an electronic database of real-time primary care records indicate that a minority of women with pelvic inflammatory disease receive investigation and treatment according to guidelines. Further research is needed to understand the delivery of care in general practice.

population, with data from 460 practices, broadly representative of the UK population. There are 3.5 million currently active patients. Records are derived from the GP computer system (VISION) and contain complete prescribing and coded diagnostic and clinical information, as well as information on tests requested, laboratory results, and referrals made at or following on from each consultation. The structure of the data is shown in Figure 1, with different parts of data held in separate record tables. Practice-level data include a deprivation index score based on the postcode of the practice and the NHS region in which the practice is based. In 200 out of 460 (approximately 40\%) practices, a Townsend deprivation index score based on the small area level is available for each patient.

\section{Identification of cases}

The target population was all women permanently registered with a practice that met GPRD data reporting standards. All women with a first coded diagnosis of PID, who were aged $15-40$ years at the time of diagnosis, during the study period 30 June

Figure 1. Structure of the GPRD database.

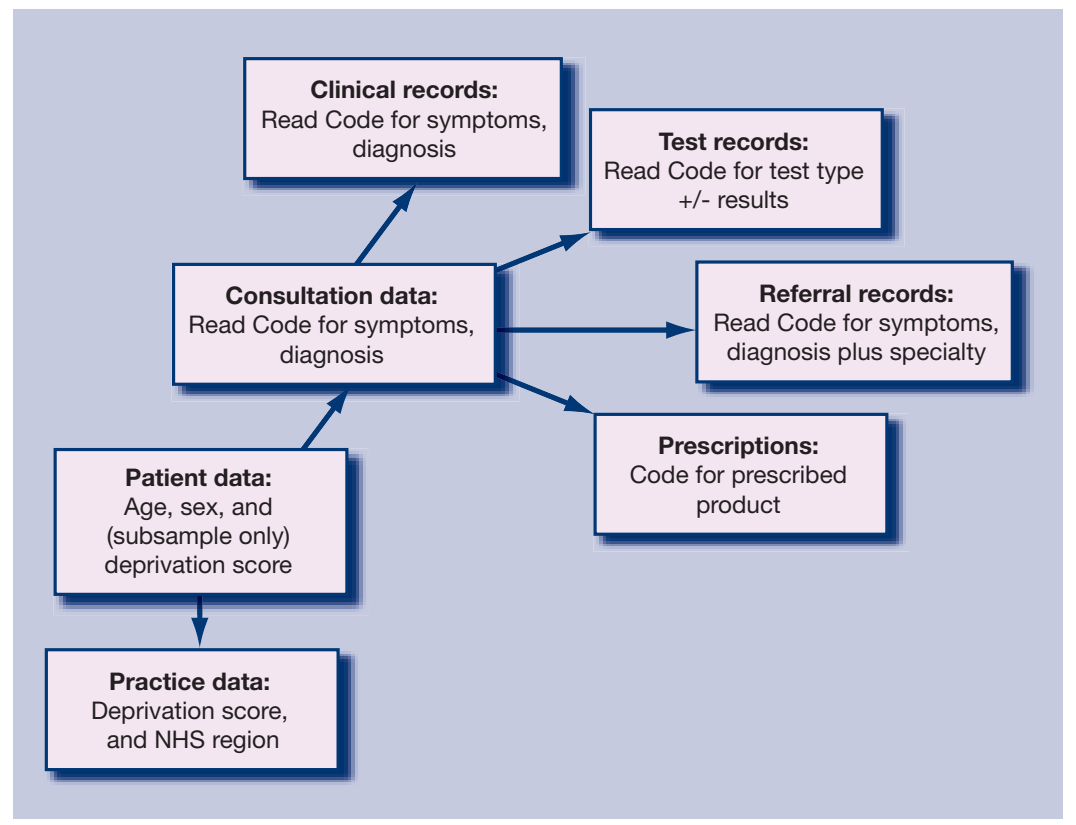


2003 to 30 June 2008, were identified. Code lists used for the definition of cases are included in Appendix 1. The code lists focused on acute cases, so that women with a code for chronic PID or its sequelae before the first acute code were excluded. Because the study research question concerns management, only codes that the researchers thought indicated that the GP was confident of the diagnosis of PID were used. Codes where the diagnosis may have been in doubt such as 'female pelvic infection' were excluded. Women with a coded diagnosis relating to pregnancy, miscarriage, or therapeutic abortion 60 days before to 28 days after the date of the PID code were not included in the analyses, and nor were temporary patients.

If there were multiple PID diagnostic codes for an individual, the date of the first one was used as the index date. Analyses were restricted to records in the period 28 days before and after the index date. If the index date was within 28 days of the start or end of the registration at the practice, the case was excluded from the final management analyses.

\section{Analysis of management}

Four aspects of the management of the PID patients were assessed.

Testing. A chlamydia test was considered to have been carried out if there was either a code for a test (for example, 'chlamydia antigen test') or a diagnosis of relevant chlamydial infection (for example, 'female chlamydial pelvic inflammatory disease'), using an approach developed in previous work. ${ }^{9}$ Codes were identified for tests for Neisseria gonorrhoea. Nonspecific microbial tests were considered to have been carried out if there was either a code for appropriate swab (for example, 'high vaginal swab'), or a test such as microscopy, culture, and sensitivities with no location given. Code lists are included in Appendix 1.

Treatment. Using prescription data, variables were created for each of the following treatments:

- all antibiotics - based on British National Formulary heading 0501; and

- specific antibiotics - based on guidelines (2005 and 2006), ${ }^{3-5}$ recommended treatment for PID was defined as any one of erythromycin, ofloxacin, azithromycin, or doxycycline, with or without metronidazole. Code lists were drawn up using drug substance name and including all formulations except for inappropriate topical preparations. Dosage and duration of use were not assessed, since this is a complex task and resources were limited. Although it is optional for milder cases in guidelines, the use of metronidazole has been highlighted in these analyses as a marker of the most complete treatment.

Evidence of care elsewhere. It was considered that a woman with a diagnostic code for PID had received care for PID in another healthcare setting if any one of the following conditions were met:

- a diagnostic code for the condition within the referral record (Figure 1);

- a suggestive symptom code within the referral record (for example, 'pelvic pain'); or

- a code anywhere in the records indicating care elsewhere (for example, 'referral to A\&E', 'seen in GUM clinic'). This category also included less specific terms such as 'discharge summary' or 'letter from specialist'.

Evidence of management only within practice. If there was no evidence of care elsewhere and there was evidence of any treatment (any antibiotic prescription) or testing (including non-specific microbial tests) within the practice, these cases were considered to have been managed within the practice only. This group alone was used for the investigation of quality of management in general practice as it did not seem appropriate to include cases where important parts of the care may have been delivered outside the general practice, and hence not necessarily recorded on the database. Women with no evidence of either management within the practice or care elsewhere were also not included in the quality of management analyses, due to concerns about completeness of recording in these cases.

\section{Statistical analysis}

The data were prepared using Stata (version 10; Statacorp LP, Texas). Calendar years were defined as mid-years from 30 June so that year 2003 covered 30 June 2003 to 29 June 2004, and so on.

Denominator data, by single year age groups and calendar year, were used to calculate the incidence rates in specific age groups and years by dividing the number of cases by the appropriate denominator. Age-standardised rates were then obtained by applying these rates to the European standard population. Differences in incidence rates over time and age groups were assessed using Poisson regression.

For analyses of management, first the proportion of cases with the various management markers in different study years and age groups was calculated. Logistic regression models were then used to investigate factors associated with different management locations, testing, and treatment 
patterns. A series of sensitivity analyses were performed, extending the window for analysis of management from 28 to 42,60 , and 90 days either side of the index date, to assess whether relevant data were being missed by using the 28-day window.

\section{RESULTS}

Figure 2 summarises the identification and exclusion of cases; 4724 women with a first coded episode of PID during the study period were identified from a population of 2.8 million woman-years of observation. Of these, 927 had evidence of a recent pregnancy and were excluded, leaving 3797 cases for the incidence analyses. The median age of the included women was 25 years (interquartile range $20-31$ years).

\section{Incident cases available for the study}

The incidence of first episode of PID seen in general practice fell during the study period, from $19.3 / 10000$ person-years in 2003 to $8.9 / 10000$ person-years in 2007. The incidence rate was highest in women aged 20-24 years, and rose from 28.4 to $30.4 / 10000$ person-years between 2003 and 2004 but then fell to $14.2 / 10000$ person-years in 2007. Incidence in all other age-groups fell progressively from 2003 to 2007 , with the greatest decline in younger age groups $(P=0.04$ for interaction in Poisson models).

\section{Management of PID}

Location of management. One hundred and twentyeight women in whom the index date of the first episode was within 28 days of the start or end of their GP records were excluded, leaving 3669 cases of PID (Table 1); $34 \%$ of women with a PID diagnosis had evidence of having received care elsewhere, and this proportion increased during the study period ( $P$ for trend $<0.001)$. To validate the classification of location of management, the proportions of women who received treatment or testing within the practice were compared in women with and without evidence of care elsewhere. Evidence of care outside general practice was associated with a $40 \%$ reduction in odds of having either recommended treatment or a $C$. trachomatis test within general practice (odds ratio $[\mathrm{OR}]=0.6$; $95 \%$ confidence interval $[\mathrm{Cl}]=0.5$ to 0.7 for both). The proportion of cases with evidence of management only within the GP practice declined over time $(P<0.001)$, commensurate with the rise in cases with care elsewhere. Ten per cent of women had no evidence of either management within practice or care elsewhere, and this proportion also declined over time.

Management within practice in comparison to guidelines. Of the 2064 PID cases managed only

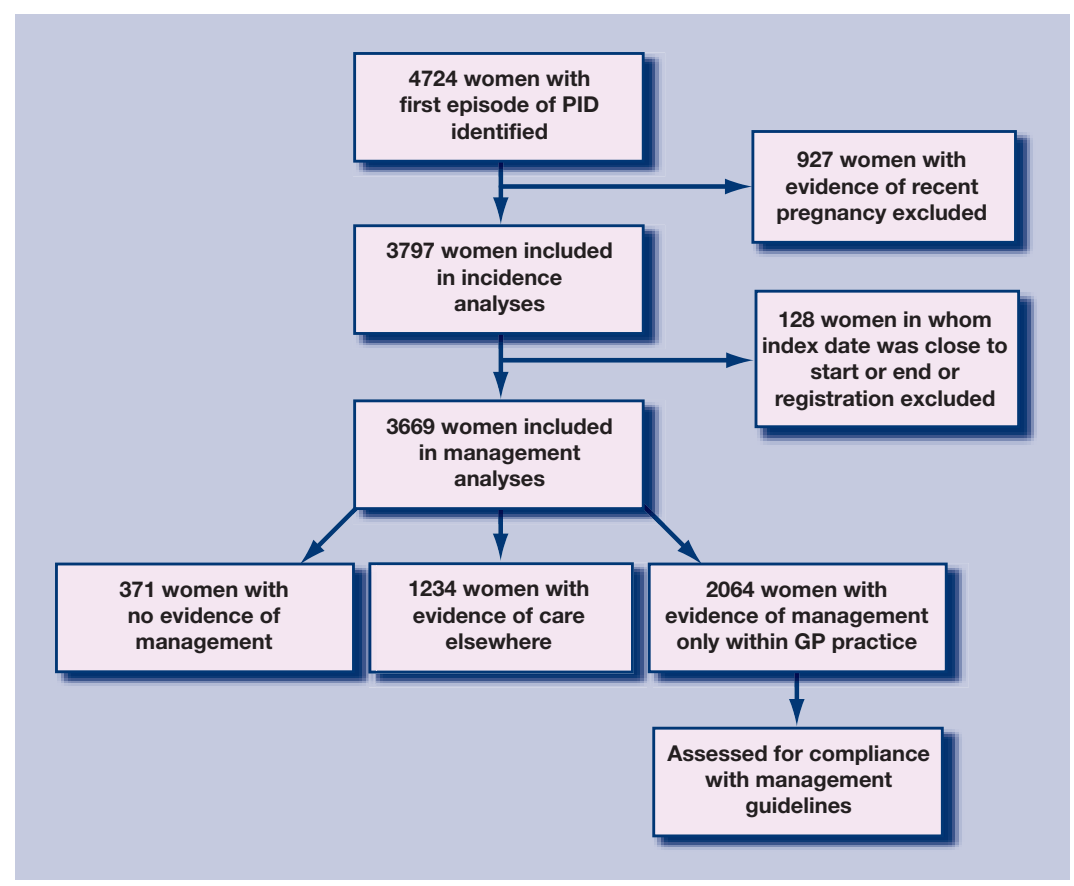

within practice, $60 \%$ of these women received recommended treatment (of which 34\% included metronidazole) (Table 2); $56 \%$ had received a $C$. Figure 2. Flow chart of study: patient identification and exclusions. trachomatis test, and $50 \%$ a non-specific microbial test; $36 \%$ received optimal treatment with the recommended antibiotic and a C. trachomatis test, but only $16 \%$ had had a C. trachomatis test and treatment including metronidazole. The absolute numbers of cases managed within practice declined steeply during the study period, due both to declining overall incidence and the increasing proportion with evidence of care elsewhere. The proportion of women receiving recommended treatment increased during the study period, but there were no clear trends in testing over time. Sensitivity analyses, shown in Appendix 2, show that the proportion of cases with evidence of care elsewhere increased as the window widened, but for patients managed within the practice, the pattern of care was similar.

Table 1. Location of management of PID cases seen in primary care.

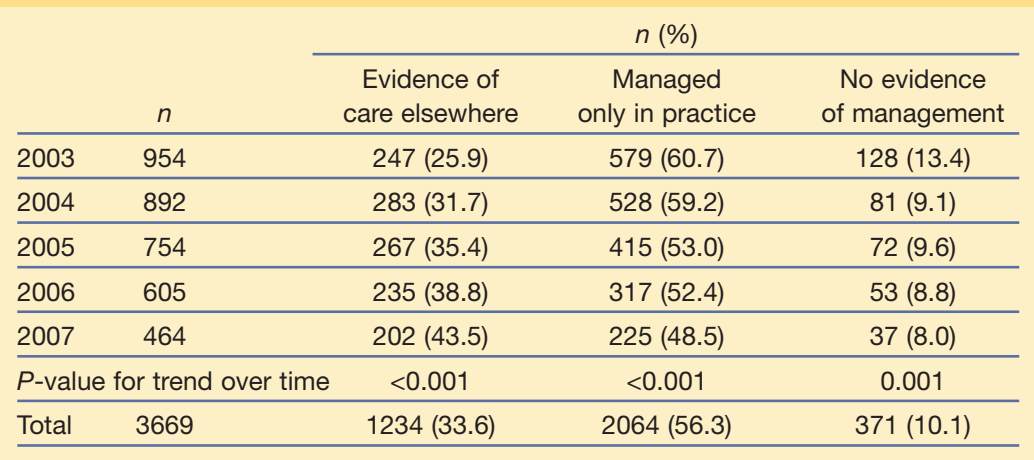


Table 2. Quality of management of PID cases managed within practice only.

$n(\%)$

\begin{tabular}{|c|c|c|c|c|c|c|c|c|}
\hline & \\
\hline & $N$ & $\begin{array}{c}\text { Chlamydia } \\
\text { trachomatis test }\end{array}$ & Non-specific test & $\begin{array}{c}\text { Neisseria } \\
\text { gonorrhoea test }\end{array}$ & $\begin{array}{c}\text { Recommended } \\
\text { treatment }\end{array}$ & $\begin{array}{l}\text { Recommended } \\
\text { treatment } \\
\text { (including } \\
\text { metronidazole) }\end{array}$ & $\begin{array}{c}\text { Recommended } \\
\text { treatment }+ \\
\text { Chlamydia } \\
\text { trachomatis test }\end{array}$ & $\begin{array}{l}\text { Recommended } \\
\text { treatment including } \\
\text { metronidazole + } \\
\text { Chlamydia } \\
\text { trachomatis test }\end{array}$ \\
\hline 2003 & 579 & 306 (52.9) & $299(51.6)$ & $4(0.7)$ & 331 (57.2) & $195(33.7)$ & $180(31.1)$ & $74(12.8)$ \\
\hline 2004 & 528 & 297 (56.3) & $246(47.0)$ & $3(0.6)$ & $304(57.6)$ & $161(30.5)$ & $180(34.1)$ & $67(12.7)$ \\
\hline 2006 & 317 & $181(57.1)$ & $157(49.5)$ & $9(2.8)$ & $210(66.3)$ & $126(39.8)$ & $130(41.0)$ & 64 (20.2) \\
\hline 2007 & 225 & $130(57.8)$ & $114(50.7)$ & $20(8.9)$ & $152(67.6)$ & $98(43.8)$ & $97(43.1)$ & $51(22.7)$ \\
\hline \multicolumn{2}{|c|}{$\begin{array}{l}P \text {-value for trend } \\
\text { over time }\end{array}$} & 0.116 & 0.914 & $<0.001$ & 0.001 & 0.003 & $<0.001$ & $<0.001$ \\
\hline \multicolumn{2}{|c|}{ Total 2064 (100) } & $1157(56.1)$ & $1028(49.8)$ & $50(2.4)$ & $1238(60.0)$ & 708 (34.3) & $737(35.7)$ & $320(15.5)$ \\
\hline
\end{tabular}

Patient and practice-level associations with optimal treatment. Determinants of optimal treatment (C. trachomatis test with recommended treatment with or without metronidazole) were examined in logistic regression models. Multivariate models confirmed optimal treatment was more likely in later years of the study. Women in their 30 s were less likely to receive optimal treatment (Table 3). Although there were some differences in optimal management across the quintiles of practice deprivation, there was no evidence of linear trend with increasing deprivation (OR for linear variable $=1.0[95 \% \mathrm{Cl}=0.9$ to 1.0$]$ ). Similarly, no association with deprivation was seen in the subsample for which individual Townsend deprivation index quintile was available $(n=982, P$ from likelihood ratio test for inclusion of deprivation quintile $=0.55$ ). Results were similar when multilevel logistic regression models were run with a random intercept including practice as a higher-level variable.

\section{DISCUSSION}

\section{Summary of main findings}

The study results confirm that a substantial caseload of PID is seen and diagnosed in UK primary care. A fall in incidence of diagnosed cases was seen between 2003 and 2008. The results indicate, however, that only a minority of PID cases managed within primary care received treatment and investigations according to guidelines. Overall, only $16 \%$ of women received both a $C$. trachomatis test and recommended treatment, including metronidazole. Women seen later in the study period were more likely to have received care that followed guidelines $(23 \%$ received testing and treatment including metronidazole in 2007), as were younger women. Practice-level deprivation did not affect the recorded management of patients.

\section{Strengths and limitations of the study}

This study used real-time patient records and so it was possible to assess the care that unselected patients receive, avoiding the problems of response and reporting bias that are inherent in self-report data. However, these databases are designed for patient care and not for research. Only coded data were used in these analyses, and it was not possible to include any information that was entered as free text in the GP records. This may have resulted in misclassification of patients both as cases and into the different management groups.

Table 3. Determinants of optimal management ${ }^{\mathrm{a}}$ within practice.

\begin{tabular}{lccccc} 
& \multicolumn{5}{c}{ Age group (years) } \\
\cline { 2 - 6 } & $15-19$ & $20-24$ & $25-29$ & $30-34$ & $35-40$ \\
\hline Adjusted OR $(95 \% \mathrm{Cl})$ & 1 & $0.9(0.7$ to 1.1$)$ & $0.6(0.5$ to 0.8$)$ & $0.5(0.3$ to 0.7$)$ & 0.4 (0.3 to 0.6) \\
\hline Event year & 2003 & 2004 & 2005 & 2006 & 2007 \\
\hline Adjusted OR $(95 \% \mathrm{Cl})$ & 1 & $1.1(0.9$ to 1.5$)$ & $1.2(0.9$ to 1.6$)$ & $1.6(1.2$ to 2.2$)$ & $1.8(1.3$ to 2.5$)$ \\
\hline $\begin{array}{l}\text { Practice location: } \\
\text { quintile of deprivation }\end{array}$ & 1 & 2 & 3 & 4 & 5 \\
\hline Adjusted OR $(95 \% \mathrm{Cl})$ & 1 & $1.5(1.1$ to 2.1$)$ & $1.3(0.9$ to 1.8$)$ & $1.6(1.2$ to 2.2$)$ & 1.1 (0.8 to 1.5$)$ \\
\hline
\end{tabular}

aptimal management $=\mathrm{C}$. trachomatis test and recommended antibiotic treatment with or without metronidazole. 
The clinical diagnosis of PID is subjective, with definitive diagnosis relying on laparoscopy which is not routinely used. Doxanakis et al showed substantial differences in the diagnostic rates of PID between genitourinary medicine specialists in Australia. ${ }^{14}$ This is also likely to be true between GPs. Once a diagnosis is made, GPs may vary in their use of Read Codes, so that a condition may be entered either as diagnosis or as presenting symptom. In order to maintain high specificity, no presenting symptoms were included as diagnostic codes. Ratelle et al showed that PID diagnostic codes alone in secondary care were a poor predictor of clinically verified PID. ${ }^{15}$ If this is also the case in primary care, some of the cases in the present study may not have actually been PID. Although there are no validation data to address this issue, the key question for this study is whether the GP thought the patient had PID and whether they were then managed appropriately; such as, whether the diagnostic code accurately reflects the GP's opinion. Further research is needed to understand how GPs code such complex clinical conditions.

The classification of location of management was complex. The use of the referral record by GPs was used as evidence of referral, but it is unclear how accurately these separate records are used in practice by GPs. Some of the Read Codes taken as evidence of care elsewhere were relatively nonspecific and may have not actually been related to the PID diagnosis. As expected, as the management window widened, the proportion of women with evidence of care elsewhere increased, but this may have included unrelated referrals. Similarly, it is possible the recommended treatment was given for conditions other than PID. However, in sensitivity analyses the estimates of treatment were not dependent on the length of the management window.

\section{Comparison with existing literature}

Previous papers reporting incidence of PID in UK primary care have studied total episodes not just first episodes. Simms and coworkers, using two different primary care systems, reported incidence rates up to 10 times higher than those of the present study: with 251/10 000 person-years for 20-24 year olds in 1991 , and 150/10 000 for 25-44 year olds in 2001. , $^{6}$ Other work using the GPRD has found an incidence of 28.1/10 000 person-years for women aged 16-44 years between 2000 and 2008. ${ }^{16}$ The incidence levels for PID reported in this study are lower because the incidence estimates are not for surveillance but to estimate management case load in general practice. A more restricted code list was used to increase specificity, first episodes only were counted, and cases where the infection may have arisen in relation to childbirth or miscarriage were excluded.

The study found a marked fall in the incidence of first-episode coded PID in primary care, with rates falling by more than $50 \%$. Declining incidence of PID diagnosed in general practice in the UK has been documented since $1994,{ }^{7}$ and its relationship to the English NCSP is at yet unclear. ${ }^{16}$ The study data may reflect a true fall in incidence of the disease, but alternative explanations need to be considered. These include changes in patterns of care - with more cases seen in other settings - or changes to coding or recording of data. Recent changes in GP coding and recording behaviour have been substantial, following the introduction of the Quality and Outcomes Framework targets. It is possible that such changes have led to an apparent fall in PID incidence. However, PID is not included in any Quality and Outcomes Framework targets, and for improved coding to lead to a fall in incidence would imply that previous estimates were too high. The trend found of increasing evidence of care elsewhere might support change in the pattern of care as an explanation. However, reports from other countries that include data from all healthcare settings have shown a similar trend with falling incidence. ${ }^{17,18}$ If incidence is falling, it may be due to the chlamydia screening programme or may reflect a change in pathogenicity of causative organisms.

\section{Implications for clinical practice and future research}

The results overall raise some concerns about the completeness of management of PID in primary care, although the trend of improved management over time is encouraging. Although $70 \%$ of women with PID had received recommended treatment and 54\% a C. trachomatis test, only $16 \%$ had received both. $A$ postal questionnaire survey of UK GPs in 1994 found that $63 \%$ reported prescribing appropriate antichlamydia treatment and $45 \%$ reported testing for $C$. trachomatis. ${ }^{11}$ Overall, these figures are very similar to the estimates of the present study, and suggest education could still be improved. Women in their 20 s are more likely to receive recommended management. It was reassuring that neither patient nor practice deprivation level were associated with following management guidelines.

Cases of PID recorded in primary care were more likely to show evidence of care received elsewhere in the later years of the study period. This trend towards greater care elsewhere is somewhat surprising and goes against what might have been expected from the recommendations of the Department of Health review. ${ }^{10}$ It is possible that 
these trends represent better recording of referral and hospital events by GPs rather than any actual change in pattern of care.

These analyses, using coded data from an electronic records database, suggest that the management of PID in UK primary care, although improving, does not follow recommended guidelines for the majority of women. Further initiatives are required to improve the management of women with PID and to understand any barriers to care. However, the accuracy of the coded information in primary care databases needs to be confirmed and the authors plan to consult anonymised free text in a selection of cases to investigate whether textual data alter the case definition and estimates of incidence and management.

\section{Funding body}

Access to the GPRD database was funded through the Medical Research Council's licence agreement with the Medicines and Healthcare products Regulatory Agency.

\section{Ethics committee}

The study was approved by the MHRA Independent Scientific Advisory Committee (protocol number 08_097).

\section{Competing interests}

The authors have stated that there are none.

\section{Acknowledgements}

Access to the GPRD database was funded through the Medical Research Council's licence agreement with the MHRA.

\section{Discuss this article}

Contribute and read comments about this article on the Discussion Forum: http://www.rcgp.org.uk/bjgp-discuss

\section{REFERENCES}

1. Hillis SD, Joesoef R, Marchbanks PA, et al. Delayed care of pelvic inflammatory disease as a risk factor for impaired fertility. Am I Obstet Gynecol 1993; 168(5): 1503-1509.

2. British Association for Sexual Health and HIV. 2001 National guideline for the management of epididymo-orchitis http://www.bashh.org/documents/31/31.pdf (accessed 26 Aug 2010).

3. British Association for Sexual Health and HIV. United Kingdom National Guidelines for the management of pelvic inflammatory disease. http://www.bashh.org/documents/118/118.pdf (accessed 26 Aug 2010)

4. British Association for Sexual Health and HIV. 2006 UK National
Guidelines for the management of genital tract infection with Chlamydia trachomatis.

http://www.bashh.org/documents/61/61.pdf (accessed 26 Aug 2010).

5. Royal College of Obstetricians and Gynaecologists. Management of acute pelvic inflammatory disease. Guideline no 32

http://www.rcog.org.uk/files/rcog-corp/uploaded-

files/T32PelvicInflamatoryDisease2008MinorRevision.pdf (accessed 4 Jun 2010)

6. Simms I, Rogers P, Charlett A. The rate of diagnosis and demography of pelvic inflammatory disease in general practice: England and Wales. Int J STD AIDS 1999; 10(7): 448-451.

7. Simms I, Fleming DM, Lowndes CM, et al. Surveillance of sexually transmitted diseases in general practice: a description of trends in the Royal College of General Practitioners Weekly Returns Service between 1994 and 2001. Int J STD AIDS 2006; 17(10): 693-698.

8. Cassell JA, Mercer CH, Sutcliffe L, et al. Trends in sexually transmitted infections in general practice 1990-2000: population based study using data from the UK general practice research database. BMJ 2006; 332(7537): 332-334.

9. Hughes G, Williams T, Simms I, et al. Use of a primary care database to determine trends in genital chlamydia testing, diagnostic episodes and management in UK general practice, 1990-2004. Sex Transm Infect 2007; 83: 310-313.

10. Department of Health. Better prevention, better services, better sexual health: the national strategy for sexual health and HIV. London: Department of Health, 2001.

11. Huengsberg M, Ip CB, Radcliffe KW. How well is pelvic inflammatory disease managed in general practice? A postal questionnaire survey. Sex Transm Infect 1998; 74(5): 361-363.

12. National Chlamydia Screening Programme. The National Chlamydia Screening Programme Core requirements, 2008. http://www.chlamydiascreening.nhs.uk/ps/assets/pdfs/core_req/NS CP_CoreReq_4th_edition_latest.pdf (accessed 4 Jun 2010).

13. The General Practice Research Database. http://www.gprd.com/home/ (accessed 4 Jun 2010).

14. Doxanakis A, Hayes RD, Chen MY, et al. Missing pelvic inflammatory disease? Substantial differences in the rate at which doctors diagnose PID. Sex Transm Infect 2008; 84(7): 518-523.

15. Ratelle S, Yokoe D, Blejan C, et al. Predictive value of clinical diagnostic codes for the CDC case definition of pelvic inflammatory (PID) - implications for surveillance. Sex Transm Dis 2003; 30(11): 866-870.

16. French $\mathrm{C}$, Hughes G, Yung M, et al. Rates of pelvic inflammatory disease diagnoses in general practice prior to and during the initial years of an opportunistic chlamydia screening programme. Sex Transm Dis 2010: in press.

17. Owusu-Edusei K, Bohm MK, Chesson HW, Kent CK. Chlamydia and gonorrhoea screening and pelvic inflammatory disease diagnoses: can simple time series analyses provide some insights? Oral presentation at 18th Conference of International Society for STD Research, London 2009, OS.2.6.06.

18. Rekart M, Gilbert M, Kim P, et al. Documenting the success of Chlamydia control in British Columbia. 2009. Poster presentation at 18th Conference of International Society for STD Research, London 2009. P.4.64. 
Appendix 1. Code lists:

A. Diagnostic codes for pelvic inflammatory disease.

\begin{tabular}{|c|c|c|}
\hline GPRD medical code & Read/OXMIS term & Read/OXMIS Code \\
\hline 271330 & Female pelvic inflammatory disease NOS & $\mathrm{K} 4 \mathrm{z} . .00$ \\
\hline 216451 & Other specified female pelvic inflammatory disease & K4y..00 \\
\hline 262041 & Female gonococcal pelvic inflammatory disease & K44..00 \\
\hline 225561 & PID - pelvic inflammatory disease & $\mathrm{K} 40 \mathrm{z} .13$ \\
\hline 243685 & PID & K40z.11 \\
\hline 271318 & Female pelvic inflammatory diseases NOS & K40z.00 \\
\hline 207468 & Female chlamydial pelvic inflammatory disease & K40y100 \\
\hline 289486 & Acute pelvic inflammatory disease & K409.00 \\
\hline 262035 & Acute pelvic inflammatory disease & K406.11 \\
\hline 262034 & Acute parametritis & K403000 \\
\hline 234667 & Acute parametritis and pelvic cellulitis & K403.00 \\
\hline 252797 & Unspecified salpingitis and oophoritis NOS & K402z00 \\
\hline 225555 & Perisalpingitis unspecified & K402700 \\
\hline 207465 & Salpingitis unspecified & K402600 \\
\hline 252796 & Salpingo-oophoritis unspecified & K402500 \\
\hline 207464 & Perioophoritis unspecified & K402400 \\
\hline 289481 & Oophoritis unspecified & K402300 \\
\hline 280371 & Salpingitis and oophoritis unspecified & K402.00 \\
\hline 262032 & Acute salpingitis and oophoritis NOS & K400z00 \\
\hline 216441 & Acute perisalpingitis & $\mathrm{K} 400400$ \\
\hline 234664 & Acute salpingitis & K400300 \\
\hline 298752 & Acute salpingo-oophoritis & K400200 \\
\hline 271313 & Acute perioophoritis & K400100 \\
\hline 207462 & Acute oophoritis & K400000 \\
\hline 298751 & Oophoritis - acute & K400.11 \\
\hline 280367 & Acute salpingitis and oophoritis & K400.00 \\
\hline 234663 & Ovarian, fallopian tube and pelvic inflammatory diseases & K40..00 \\
\hline 243681 & Female pelvic inflammatory diseases & $\mathrm{K} 4 \ldots 00$ \\
\hline 269816 & Acute gonococcal salpingitis & A981700 \\
\hline 304410 & PELVIC INFLAMMATION FEMALE & $6160 \mathrm{FL}$ \\
\hline 238388 & PERIOOPHORITIS & $614 \mathrm{PP}$ \\
\hline 238387 & PERISALPINGITIS & $614 \mathrm{PL}$ \\
\hline 284301 & OOPHORITIS & $614 \mathrm{~B}$ \\
\hline 304403 & SALPINGO-OOPHORITIS & $614 \mathrm{~A}$ \\
\hline 211327 & OOPHORITIS ACUTE & $612 \mathrm{P}$ \\
\hline 229476 & SALPINGITIS ACUTE & $612 \mathrm{~L}$ \\
\hline 219863 & OOPHORITIS GONOCOCCAL & 0981B \\
\hline 256278 & SALPINGITIS GONOCOCCAL & $0981 \mathrm{~A}$ \\
\hline 207522 & [X]Inflammatory diseases of female pelvic organs & Kyu8.00 \\
\hline 214967 & Chlamydial inf of pelviperitoneum oth genitourinary organs & A78А300 \\
\hline 265498 & SYNDROME FITZHUGH CURTIS & 0988FC \\
\hline 278875 & Fitzhugh Curtis syndrome & A98y600 \\
\hline 289351 & Chlamydial peritonitis & $\mathrm{J} 550400$ \\
\hline
\end{tabular}




\begin{tabular}{|c|c|c|}
\hline GPRD medical code & Read/OXMIS term & Read/OXMIS Code \\
\hline 205965 & Chlamydial infection, unspecified & A78AW00 \\
\hline 205969 & Other viral or chlamydial disease NOS & A7z..00 \\
\hline 206063 & [X]Other chlamydial diseases & Ayu6100 \\
\hline 207468 & Female chlamydial pelvic inflammatory disease & K40y100 \\
\hline 214967 & Chlamydial inf of pelviperitoneum oth genitourinary organs & A78А300 \\
\hline 215059 & {$[X]$ Chlamydial infection, unspecified } & Ayu6200 \\
\hline 225563 & Chlamydia cervicitis & K420900 \\
\hline 242170 & Chlamydial infection of genitourinary tract, unspecified & A78AX00 \\
\hline 242258 & {$[\mathrm{X}]$ Chlamydial infection of genitourinary tract, unspecified } & Ayu4K00 \\
\hline 251351 & Chlamydial infection of lower genitourinary tract & A78A000 \\
\hline 258276 & Chlamydia antigen by ELISA & $43 \cup 0.00$ \\
\hline 267536 & Chlamydia antigen test & 43U..00 \\
\hline$\underline{278838}$ & Other viral and chlamydial diseases & A7 ...00 \\
\hline 278847 & Other viral or chlamydial diseases & A78..00 \\
\hline 278852 & Chlamydial infection & A78A.00 \\
\hline 280340 & Chlamydial epididymitis & K241600 \\
\hline 285745 & Chlamydia antigen ELISA positive & $43 U 1.00$ \\
\hline 285746 & Chlamydia antigen ELISA negative & $43 \cup 2.00$ \\
\hline 287974 & Other specified viral and chlamydial diseases & A78y.00 \\
\hline 289351 & Chlamydial peritonitis & J550400 \\
\hline 297184 & Chlamydial infection of anus and rectum & A78A200 \\
\hline 297190 & Other specified viral or chlamydial diseases & A7y..00 \\
\hline 297288 & [X]Other diseases caused by chlamydiae & Ayu 6.00 \\
\hline 302966 & INFECTION CHLAMYDIAL & 0399C \\
\hline 302967 & CHLAMYDIA TRACHOMATIS & 0399CT \\
\hline 307938 & Chlamydia trachomatis IgG level & $43 \mathrm{eJ} .00$ \\
\hline 308079 & Chlamydia trachomatis L2 antibody level & $43 \mathrm{eC} .00$ \\
\hline 308199 & Chlamydia group complement fixation test & $43 \mathrm{eF} .00$ \\
\hline 308461 & Chlamydia antibody level & $43 \mathrm{eE} .00$ \\
\hline 308950 & Chlamydia trachomatis polymerase chain reaction & $43 \mathrm{~h} 0.00$ \\
\hline 309472 & Chlamydia group antibody level & 43WM.00 \\
\hline 309613 & Chlamydia trachomatis IgM level & $43 e z .00$ \\
\hline 309766 & Endocervical chlamydia swab & 4JK9.00 \\
\hline 309829 & Urethral chlamydia swab & 4JKA.00 \\
\hline 332003 & Chlamydia trachomatis IgA level & $43 n 9.00$ \\
\hline 342066 & Chlamydia trachomatis antigen test & 43U3.00 \\
\hline 342214 & Chlamydia deoxyribonucleic acid detection & 43jK.00 \\
\hline 342310 & Chlamydia serology & 4JDM.00 \\
\hline 343726 & Urine screen for chlamydia & $68 \mathrm{~K} 7.00$ \\
\hline 343949 & Chlamydia PCR positive & $43 \cup 4.00$ \\
\hline 343968 & Chlamydia PCR negative & $43 \cup 5.00$ \\
\hline 344624 & Urine chlamydia trachomatis test positive & $46 \mathrm{H} 6.00$ \\
\hline 344736 & Urine chlamydia trachomatis test negative & $46 \mathrm{H} 7.00$ \\
\hline 345942 & Chlamydia screening declined & $813 \mathrm{~T} .00$ \\
\hline 346998 & Chlamydia screening counselling & 677L.00 \\
\hline 347186 & Chlamydia trachomatis contact & 65PJ.00 \\
\hline 347227 & Low vaginal swab for chlamydia taken by patient & 4JKD.00 \\
\hline 347301 & Chlamydial infection of genital organs NEC & A78A500 \\
\hline 347315 & Chlamydia test offered & $90 q 0.00$ \\
\hline 347970 & Chlamydia test positive & $43 \cup 8.00$ \\
\hline 348085 & Chlamydia test negative & $43 \cup 6.00$ \\
\hline 348329 & Chlamydia test equivocal & $43 \cup 7.00$ \\
\hline
\end{tabular}




\section{Appendix 1. Code lists: \\ C. Tests for Neisseria gonorrhoea.}

\begin{tabular}{lll} 
GPRD medical code & Read/OXMIS term & Read/OXMIS Code \\
\hline 249090 & Gonorrhoea infect. titre test & $43 E 6.00$ \\
\hline 309228 & Neisseria gonorrhoeae polymerase chain reaction & $43 \mathrm{~h} 6.00$ \\
\hline 309635 & Neisseria gonorrhoeae nucleic acid detection & $43 \mathrm{JA} .00$ \\
\hline 340376 & Gonococcal swab & 4JLA.00 \\
\hline 342356 & Gonococcal cervical swab & 4JKB.00 \\
\hline 343558 & Gonococcal urethral swab & 4JKC.00 \\
\hline 348093 & Gonorrhoea test positive & 4JQA.00 \\
\hline 348381 & Gonorrhoea test negative & 4JQ8.00 \\
\hline
\end{tabular}

\section{Appendix 1. Code lists: \\ D. other microbial tests.}

\begin{tabular}{|c|c|c|}
\hline GPRD medical code & Read/OXMIS term & Read/OXMIS Code \\
\hline 203712 & Infectious titres NOS & 43E..00 \\
\hline 203917 & Sample microscopy & $4 \mid 15.00$ \\
\hline 203918 & White cells seen on microscopy & $4 \mid 15100$ \\
\hline 203919 & RBCs seen on microscopy & 4115200 \\
\hline 203947 & High vaginal swab culture negative & 4JK2100 \\
\hline 203948 & HVS culture - trichomonas vaginalis & 4JK2200 \\
\hline 205666 & Refer for microbiological test & 8HP2.00 \\
\hline 210464 & PENILE SWAB CULTURE NEGATIVE & L 167DN \\
\hline 210515 & HVS TRICHOMONAS VAGINALIS & L1670FT \\
\hline 212942 & Sample culture & $4 J 17.00$ \\
\hline 212962 & Semen sent for $\mathrm{C} / \mathrm{S}$ & 4JL8.00 \\
\hline 219515 & SWAB CERVICAL ABNORMAL & L 167FC \\
\hline 219570 & HVS LACTOBACILLI & L1670FL \\
\hline 221698 & Direct microscopy & 31B1.00 \\
\hline 222017 & Sample: no organism isolated & $4 \mathrm{~J} 11.00$ \\
\hline 222018 & Sample: organism isolated & 4J12.00 \\
\hline 222020 & Sample: bacteriology - general & $4 \mathrm{~J} 2 . .00$ \\
\hline 222022 & Sensitivity - bacteriology & $4 \mathrm{~J} 2 . .13$ \\
\hline 222038 & Microbiology NOS & 4JZ..00 \\
\hline 228578 & MICROBIOLOGY REPORT ABNORMAL & L 2MA \\
\hline 228611 & HVS CULTURE NEGATIVE & L 167FN \\
\hline 228613 & SWAB CULTURE BACTERIAL GROWTH & L 167XE \\
\hline 230862 & Blood sent - infectious titres & 43E1.00 \\
\hline 231003 & Parasite in urine & $46 \mathrm{H} . .15$ \\
\hline 231090 & Microbiology & 4J...00 \\
\hline 231091 & Sample - microbiological exam & $4 J 1 . .00$ \\
\hline 231094 & Sample: dir.micr.:no organism & $4 J 71.00$ \\
\hline 231095 & Bacteria on microscopy & $4 J 72.11$ \\
\hline 231108 & Urethral swab culture positive & 4JK1000 \\
\hline 231109 & High vaginal swab: white cells seen & 4JK2500 \\
\hline 231110 & Vaginal swab culture negative & 4JK6.00 \\
\hline 237538 & MICROBIOLOGY REPORT & L 2MR \\
\hline 237571 & VAGINAL SWAB CULTURE POSITIVE & L 167FZ \\
\hline 237574 & SWAB CULTURE FUNGAL GROWTH & L 167XC \\
\hline
\end{tabular}




\begin{tabular}{|c|c|c|}
\hline 237587 & VIRAL TITRES & L 189D \\
\hline 237617 & HVS GARDNERELLA VAGINALIS & L1670FG \\
\hline 237618 & HVS YEAST & L1670FY \\
\hline 240066 & Sample: direct micr. organism & $4 \mathrm{~J} 7 . .00$ \\
\hline 240075 & High vaginal swab culture positive & 4JK2000 \\
\hline 240076 & HVS culture - gardnerella vaginalis & 4JK2300 \\
\hline 240077 & Low vaginal swab taken & 4JK3.00 \\
\hline 240078 & Misc. sample for organism & 4JL..00 \\
\hline 246733 & SWAB CERVICAL & L 167FA \\
\hline 246735 & URETHRAL SWAB CULTURE NEGATIVE & L 167 IN \\
\hline 249028 & Swab sent to Lab & 4147.00 \\
\hline 249310 & Culture - general & 4J...11 \\
\hline 249324 & Cervical swab culture positive & 4JK5000 \\
\hline 258253 & Blood - infect. titre negative & 43E2.00 \\
\hline 258485 & Culture sensitivity & 4J15.11 \\
\hline 258486 & Sample: microbiology NOS & 4J1Z.00 \\
\hline 258503 & Urethral swab culture negative & 4JK1100 \\
\hline 258504 & Vaginal swab culture positive & 4JK7.00 \\
\hline 258505 & Penile swab culture positive & 4JK8000 \\
\hline 258506 & Penile swab culture negative & 4JK8100 \\
\hline 265145 & PENILE SWAB & L 167D \\
\hline 265146 & PENILE SWAB CULTURE POSITIVE & L 167DP \\
\hline 265197 & HVS WBC & L1670FW \\
\hline 267662 & Urine microscopy: orgs/FB's & $46 \mathrm{H} . .00$ \\
\hline 267735 & Sensitivity - microbiol. & $4 J \ldots 12$ \\
\hline 267736 & Sample: organism sensitivity & $4 J 15.00$ \\
\hline 267739 & O/E: stained micr.: organism & $4 \mathrm{~J} 8 . .00$ \\
\hline 267754 & Vaginal swab taken & 4JK..11 \\
\hline 267755 & Vulval swab taken & 4JK4.00 \\
\hline 267756 & Penile swab taken & 4JK8.00 \\
\hline 267757 & GUT swab NOS & 4JKZ.00 \\
\hline 274368 & HVS EPITHELIAL CELLS & L1670FE \\
\hline 276782 & Culture - bacteriology & 4J2..12 \\
\hline 276783 & Sample sent for culture/sensit & 4J22.00 \\
\hline 276800 & GUT sample taken for organism & 4JK..00 \\
\hline 276801 & High vaginal swab taken & 4JK2.00 \\
\hline 276802 & Cervical swab taken & 4JK5.00 \\
\hline 283373 & HVS & L 167F \\
\hline 283374 & HVS CULTURE POSITIVE & L 167FP \\
\hline 283375 & VAGINAL SWAB CULTURE NEGATIVE & L 167FY \\
\hline 285938 & Microscopy, culture and sensitivities & 4116.00 \\
\hline 285943 & Sample: bacteria cultured & 4J23.00 \\
\hline 285955 & Urethral swab taken & 4JK1.00 \\
\hline 285958 & Microbiology test & 4JQ..00 \\
\hline 292462 & MICROBIOLOGY REPORT NORMAL & L $2 \mathrm{MN}$ \\
\hline 292509 & SWAB CERVICAL NORMAL & L 167FB \\
\hline 292511 & URETHRAL SWAB CULTURE POSITIVE & L 167IP \\
\hline 292515 & SWAB CULTURE NO GROWTH & L 167XB \\
\hline 295145 & High vaginal swab: fungal organism isolated & 4JK2400 \\
\hline
\end{tabular}


Appendix 1. Code lists:

D continued. other microbial tests.

\begin{tabular}{lll}
295146 & Cervical swab culture negative & 4JK5100 \\
\hline 297019 & Microbiology report received & 9ND3.00 \\
\hline 301878 & VAGINAL SWAB & L 167FX \\
\hline 301879 & URETHRAL SWAB & L 167I \\
\hline 301882 & SWAB CULTURE YEAST GROWTH & L 167XD \\
\hline 308931 & Bacterial antibody level & 43e..00 \\
\hline 309727 & Microscopy & 4JS..00 \\
\hline 331709 & Gram stain microscopy & 4JS0.00 \\
\hline 332043 & Anaerobic culture & 4J18.00 \\
\hline 339918 & Concentrate microscopy & 4JS2.00 \\
\hline 340342 & Genital microscopy, culture and sensitivities & 4I1C.00 \\
\hline 340745 & Fluid microscopy, culture and sensitivities & 4l1D.00 \\
\hline 343815 & Semen microscopy & 49L..00 \\
\hline 343816 & Aerobic culture & 4J19.00 \\
\hline 344353 & Additional urine tests & 46h..00 \\
\hline 345784 & Culture for fungi & 4J45.00 \\
\hline 350883 & Low vaginal swab taken by patient & 4JKE.00 \\
\hline 350959 & Self taken low vaginal swab & 4JKE.11 \\
\hline
\end{tabular}

\section{Appendix 2. Results of sensitivity analyses at the 42,60 , and 90 -day management windows.}

\begin{tabular}{lccc} 
& 42 days, $\%$ & 60 days, \% & 90 days, $\%$ \\
\hline All cases in management analyses, & $n=3669$ & $n=3669$ & $n=3669$ \\
Managed in practice & 53.7 & 50.7 & 46.8 \\
No evidence of management & 9.1 & 8.0 & 6.8 \\
Evidence of care elsewhere & 37.2 & 41.2 & 46.4 \\
\hline Of those managed in practice only & $n=1971$ & $n=1862$ & $n=1719$ \\
Any recommended drug & 59.9 & 60.5 & 60.8 \\
Any recommended drug + metronidazole & 34.4 & 35.1 & 35.2 \\
Chlamydia trachomatis test & 57.0 & 57.9 & 59.0 \\
Microbial test & 52.2 & 53.8 & 55.5 \\
Chlamydia trachomatis test and any treatment & 36.3 & 37.1 & 37.6 \\
\hline
\end{tabular}

